\title{
Research on the Overall and Local Mechanical Behaviors of Steel Box Girder Cable-Stayed Bridge via Incremental Launching Construction
}

Piyun Zhang, Xinwen Jiang, Huilian Gan*

Yunnan Jiaotou Highway Construction Sixth Engineering Co., LTD, Yunnan 650034, China. E-mail: myelance@163.com

Abstract: In this paper, a large-span cable-stayed bridge with double pylons and double cable planes is employed to study the overall and local mechanical behaviors. The steel box girder bridge is constructed by incremental launching with the maximum span of $50 \mathrm{~m}$. Through the overall stress analysis, the most unfavorable stress position of the structure in the incremental launching construction is identified; the refined local stress analysis is carried out for the girder section at this position, and the local stress characteristics of the structure are studied. The mechanical performance and the applicability of incremental launching are determined by comparing four kinds of elastic cushion. This paper aims at improving the safety of incremental launching construction of steel box girder bridge, and can provide reference for similar projects.

Keywords: Incremental Launching Construction; Steel Box Girder Bridge; Overall Stress Analysis; Local Stress Analysis; Elastic Cushion; Safety

\section{Introduction}

The launching construction is to set up a prefabrication yard behind the abutment along the axis direction of the bridge, and the girders are prefabricated in sections. After assembling the precast girder segments with the completed girder segment, the girder body is pushed forward out of the prefabrication site by horizontal jack, and then the next segment of girder is prefabricated in the prefabrication yard until the jacking is completed.

At present, the incremental launching construction technology has become mature, but the related research mainly focuses on the concrete continuous girder bridge. For steel box girder launching construction, due to its cross-section form, material characteristics, local stability, no-prestress and other issues ${ }^{[1]}$, the current incremental launching construction research of concrete box girder can not be directly applied to steel box girder bridge.
Xie F carried out local stability analysis of steel box girders during the process of incremental launching on the basis of the elastic thin plate theory of small deflec$\operatorname{tion}^{[2]}$. Liu Y and Fan X. presented the dynamic reliability prediction method of the existing steel box girder considering the time-variant nonlinear correlations among the performance functions for the failure modes at the multiple control monitoring points ${ }^{[3]}$. Zhou L et al. investigated the temperature-induced static responses of a long-span suspension bridge with steel box girder under real service environmental conditions using numerical simulations and field measurements ${ }^{[4]}$. Benmohammed et al. presented the homotopy perturbation method (HPM) to predict the pre- and post-buckling behaviour of simply supported steel box beams with rectangular hollow section ${ }^{[5]}$. Wang $\mathrm{J}$ et al. proposed that the geometric

Copyright (C) 2020 Piyun Zhang et al.

doi: 10.18282/ice.v3i2.333

This is an open-access article distributed under the terms of the Creative Commons Attribution Non-Commercial License

(http://creativecommons.org/licenses/by-nc/4.0/), which permits unrestricted non-commercial use, distribution, and reproduction in any medium,

provided the original work is properly cited. 
state transfer method could realize the precise control of the geometric state of a steel box girder with ectopic installation and multi-state transition ${ }^{[6]}$. Wang $\mathrm{H}$ et al. investigated the temperature distribution of the steel box girder systematically with the structural health monitoring system (SHIMS) of the Sutong Cable-stayed Bridge $^{[7]}$.

As for the structural mechanical behavior in the process of incremental launching construction, Rosignoli, based on the error analysis of bridge boundary support construction, increased the bearing reaction force obtained from the overall analysis by 1.3 times $^{[8]}$, so as to consider the stress of steel girder; Fontan et al. ${ }^{[9]}$ proposed an optimization design method of guide girder for the incremental launching construction of bridge; Granata, Margiotta \& Aricima ${ }^{[10]}$ carried out relevant parameter analysis to study the influence of design parameters on the bridge structure in the construction process.

Kwang Hoe et al. optimized the length of the steel launching nose, span-to-depth ratio, buckling shear stress of the corrugated steel webs to ensure the safety of the concrete box girder bridges with corrugated steel webs during the incremental launching construction ${ }^{[11]}$. In response to the low stiffness of steel U-shaped girders, Wang $\mathrm{J}$ et al. utilized a local stress control strategy to avoid local yielding of the bottom plate, which realized incremental launching construction of steel U-shaped girders $^{[12]}$. Considering the structural characteristics and construction conditions of the huge steel truss girder, Ding et al. proposed a technique of incremental launching method with suspension cable stiffening chords for incremental launching construction of the continuous steel truss girder bridge ${ }^{[13]}$. Schmidt et al. ameliorated the problem that the slender supports of the bridge were prone to vortex excitation during the incremental launching construction phase by using aerodynamic L-shaped spoilers ${ }^{[14]}$. With the example of a long-span bridge whose main span is $180 \mathrm{~m}$, Chai et al. analyzed the feasibility of the incremental launching construction method without supporting piers by finite element method ${ }^{[15]}$. After analyzing different connections between steel webs and concrete bottom plates in pre-pressed concrete composite box girders with corrugated steel webs, Liang $\mathrm{S}$ et al. proposed that local connections and complex U-shape configurations were necessary for meeting structure's stress state requirements during the incremental launching construction ${ }^{[16]}$.

Zhang $^{[17]}$ combined numerical method and analytical method to study the expression and variation rule of pier reaction force and bending moment of steel box girder by analyzing the force of girder during jacking; Li et al. ${ }^{[18]}$ comprehensively used ANSYS and MATLAB software to carry out launching construction of a steel box girder. The simulation analysis and optimization were carried out, and the advantages of ANSYS and MATLAB software were fully used to effectively improve the safety of steel box girder incremental launching construction. Song ${ }^{[19]}$ carried out force analysis on the incremental steel box girder and temporary pier, studied the influence of horizontal friction force on pier in the process of pushing, and carried out corresponding optimization design; $\mathrm{Qu}^{[20]}$ established girder-shell mixed finite element and the local analysis model of steel box is used to analyze the stress of each plate of steel box under adverse working conditions in the process of pushing. A reliable solution is proposed for the case of excessive plate stress, and the stress distribution of different solutions is compared.

The previous research can enhance the understanding of structural stress characteristics in incremental launching construction and improve the accuracy of structural stress analysis. On this basis, the overall and local mechanical behavior of steel box girder in incremental launching construction of long-span cable-stayed bridge can be further studied, and the stress characteristics of steel box girder in the process of incremental launching can be analyzed precisely, and the applicability of each elastic cushion layer for pushing can be clarified, so as to ensure the launching construction of large-span steel box girder cable-stayed bridge was carried out smoothly.

\section{Project overview}

In this paper, a large-span cable-stayed bridge with double pylons and double cable planes is employed. The total length of main bridge is 860 meters, the main span is 430 meters, and the steel box girder of the main bridge is 38 meters wide and 3 meters high. It is designed according to the two-way six lanes, and non-motorized vehicle lanes and sidewalks are set on both sides. The elevation and cross-section of the main girder are shown in Figure 1 and 2. 


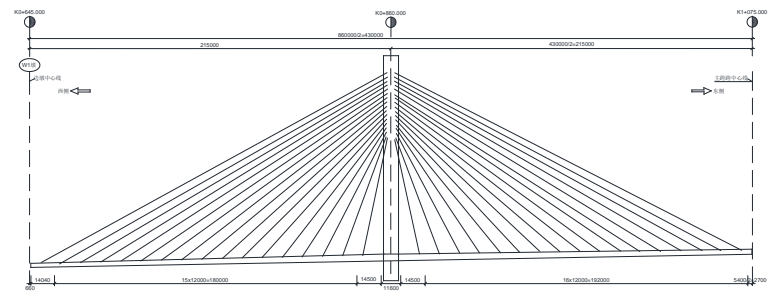

Figure 1. Elevation of main beam.

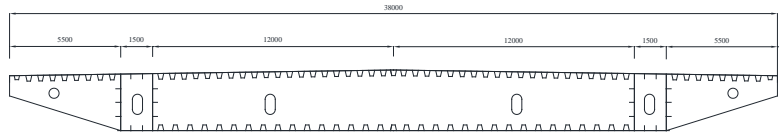

Figure 2. Section of main beam (unit: mm).

The steel box girder of the bridge is made of Q345qD material and adopts the incremental launching construction. Firstly, three segments are assembled on the assembly platform, and then the $36 \mathrm{~m}$ guide girder with Q345B material is installed. Then, the incremental launching construction is started, and a total of 9 temporary piers are set on the jacking path, with the maximum span of $50 \mathrm{~m}$. The layout of temporary pier and launching platform is shown in Figure 3.

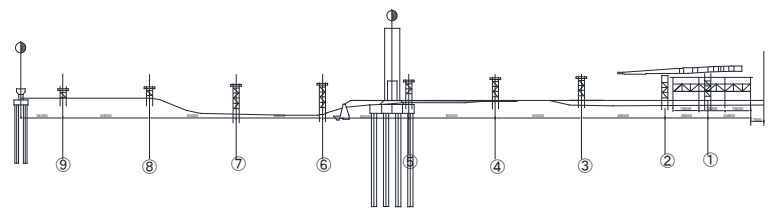

Figure 3. Elevation layout of incremental launching construction.

The thickness of top plate, bottom plate and web plate of the steel box girder is $20 \mathrm{~mm}$. The thickness of U-shaped stiffening rib of top plate and bottom plate is
$8-20 \mathrm{~mm}$, and the thickness of diaphragm plate is $16 \mathrm{~mm}$. The strength of steel plates with different thickness is different, as shown in Table $\mathbf{1}^{[21]}$.

\begin{tabular}{|c|c|c|c|c|}
\hline Grade & Thickness t or diameter $\mathbf{d}(\mathbf{m m})$ & $\begin{array}{l}\text { Tensile, compressive and flexural } \\
\qquad f\end{array}$ & $\begin{array}{l}\text { shear } \\
f_{v}\end{array}$ & $\begin{array}{c}\text { End bearing } \\
\text { (planed and pressed) } \\
f_{c e}\end{array}$ \\
\hline \multirow{5}{*}{ Q345 } & $t($ or $d) \leqslant 16$ & 305 & 175 & \multirow{5}{*}{400} \\
\hline & $16<t($ or $\mathrm{d}) \leqslant 40$ & 295 & 170 & \\
\hline & $40<\mathrm{t}($ or $\mathrm{d}) \leqslant 63$ & 290 & 165 & \\
\hline & $63<\mathrm{t}($ or $\mathrm{d}) \leqslant 80$ & 280 & 160 & \\
\hline & $80<\mathrm{t}($ or $\mathrm{d}) \leqslant 100$ & 270 & 155 & \\
\hline
\end{tabular}

Table 1. Steel strength (unit: MPa)

\section{Overall stress analysis}

\subsection{Unfavorable working conditions of steel box girder}

During the pushing process of steel box girder, the fulcrum and structural system are constantly changing. There are three kinds of unfavorable conditions for steel box girder: in front of the temporary pier on the steel guide girder, when the steel guide girder is on the temporary pier, and the steel guide beam is between the two temporary piers:

(1) Before the steel guide girder is upon the No.n\# pier, the steel box girder is in the maximum cantilever state; at this time, the stress of the steel box girder at the top of the pier fulcrum is unfavorable;

(2) After the steel guide girder is upon the No.n\# pier , the system transformation occurs, at this time, the reaction force of some pier supports is large, and the 
corresponding steel box girder on the top of pier is unfavorable;

(3) After the steel guide girder is installed on the No. $\mathrm{n} \#$ pier, in the process of pushing to $(n+1) \#$ temporary pier direction, the guide girder and the steel box girder will continue to push. The internal force of steel box girder is constantly changing under the influence of self weight difference of girder and the change of cantilever length of guide beam; the internal force distribution of steel box girder is calculated every one meter after pushing No.n\# on steel guide girder; And the continuous cal- culation and analysis show that when $\mathrm{n \#}$ pier on steel guide beam is pushed backward to $(n+1)$ \# pier to $16 \mathrm{~m}$ of guide beam cantilever, steel box girder is more unfavorable. According to the above analysis, according to the most unfavorable control principle, the calculation conditions of steel box girder in the process of incremental launching are formulated. As shown in Table 2, the calculation and analysis are carried out according to the working conditions to clarify the stress law of steel box girder in the process of pushing.

\begin{tabular}{|c|c|c|c|}
\hline \multicolumn{4}{|c|}{ Calculation condition } \\
\hline Serial number & Describe & Serial number & Describe \\
\hline 1 & $\begin{array}{c}\text { Assembly of initial three segments } \\
\text { and guide beam }\end{array}$ & 13 & Continue pushing $16 \mathrm{~m}$ \\
\hline 2 & Before upper temporary pier L3 & 14 & Before L7 of upper temporary pier \\
\hline 3 & After upper temporary pier L3 & 15 & After L7 of upper temporary pier \\
\hline 4 & $\begin{array}{c}\text { Continue pushing } 11 \mathrm{~m} \text { and start to } \\
\text { assemble lb13 / lb12 }\end{array}$ & 16 & Continue pushing $16 \mathrm{~m}$ \\
\hline 5 & Before L4 of upper temporary pier & 17 & Before L8 of upper temporary pier \\
\hline 6 & After L4 of upper temporary pier & 18 & After L8 of upper temporary pier \\
\hline 7 & Continue pushing $16 \mathrm{~m}$ & 19 & Continue pushing $16 \mathrm{~m}$ \\
\hline 8 & Before L5 of upper temporary pier & 20 & Before L9 of upper temporary pier \\
\hline 9 & After L5 of upper temporary pier & 21 & After L9 of upper temporary pier \\
\hline 10 & Continue pushing $16 \mathrm{~m}$ & 22 & Continue pushing $16 \mathrm{~m}$ \\
\hline 11 & Before L6 of upper temporary pier & 23 & Steel beam reaches design position \\
\hline 12 & After L6 of upper temporary pier & l & l \\
\hline
\end{tabular}

Table 2. Jacking calculation conditions of steel box girder

\subsection{Calculation and analysis}

The finite element model is established via the special software MIDAS Civil, and the steel box girder is simulated by beam element. According to the launching conditions of steel box girder in Table 2, the analysis is carried out one by one. With the launching, the longitudinal stress distribution of the steel box girder changes, but the maximum positive stress appears at the lower edge of the steel box girder section above the temporary pier under all working conditions, in other word, the safety state of the steel box girder is controlled by the negative bending moment at the top of the pier.

Table 3 shows the maximum stress of steel box girder under various launching conditions. From the table, during the construction process, when pushing $16 \mathrm{~m}$ steel guide girder on L8 and L9 piers, the stress of steel box girder is unfavorable, and the maximum stress of steel guide girder (condition 18) appears at L8 pier, $\sigma_{\max }=50.2 \mathrm{MPa}<\mathrm{f}=295 \mathrm{MPa}$, and the safety state of steel box girder meets the requirements. 


\begin{tabular}{l|c|c|c|c|c|c|c|c|c|c|c|c}
\hline Pushing case & 1 & 2 & 3 & 4 & 5 & 6 & 7 & 8 & 9 & 10 & 11 & 12 \\
\hline stress & 18.6 & 23.5 & 17.0 & 37.2 & 30.5 & 23 & 45.3 & 28.7 & 25.6 & 44 & 28.7 & 24.2 \\
\hline Pushing case & 13 & 14 & 15 & 16 & 17 & 18 & 19 & 20 & 21 & 22 & 23 & $/$ \\
\hline stress & 44.1 & 28.6 & 25.3 & 44.1 & 50.2 & 50.2 & 44.1 & 43.7 & 43.7 & 44.1 & 28.0 & $/$ \\
\hline
\end{tabular}

Table 3. Maximum stress of steel box girder under different launching conditions (unit: MPa)

\section{Local stress analysis}

In this paper, the shell-solid mixed nonlinear finite element model is established via ABAQUS software to analyze the local nonlinear mechanical behavior of steel box girder during incremental launching construction. The shell element S4R (four node curved thin or thick shell, reduced integral, hourglass control, finite membrane strain) is adopted for steel box girder section, and solid element C3D8R (eight node linear hexahedron element, reduced integral and hourglass control) is adopted for elastic cushion. Two reference points are set up at shell-solid contact mixed nonlinear finite element model based on ABAQUS platform. The reference points are connected with the cross-sections of the girder by coupling constraint. The shear force and bending moment at both ends sections of the $13.2 \mathrm{~m}$ girder are applied to the reference points at both ends of ABAQUS model to simulate the structural actual stress state.
On this basis, four kinds of elastic cushion are compared and analyzed: type I rubber cushion (elastic modulus 7.84 MPa), type II rubber cushion (elastic modulus $500 \mathrm{MPa}$ ), Teflon board plate (elastic modulus 1.42 GPa), steel plate (elastic modulus 2.06 GPa), and study the jacking applicability of each elastic cushion.

\subsection{Local stress characteristics of steel box girder}

The maximum Mises stress of each plate of steel box girder corresponding to each elastic cushion is shown in Table 4. According to Saint Venant's principle, the influence of elastic cushion with different stiffness on the stress of steel box girder is limited to the supporting area. Therefore, the stress distribution of the steel box girder corresponding to each elastic cushion is approximately the same, and difference of the maximum stress is small.

\begin{tabular}{ccccc}
\hline Elastic cushion & Roof & Web & Floor & Diaphragm \\
\hline Type I rubber pad & 61.1 & 131.9 & 151.8 & 92.7 \\
Type II rubber pad & 63.8 & 145.3 & 156.4 & 106.6 \\
PTEE plate & 67.2 & 151.3 & 159.4 & 111.9 \\
Steel plate & 64.3 & 288.7 & 190.4 & 113.9 \\
\hline
\end{tabular}

Table 4. Maximum Mises stress of each plate of steel box girder corresponding to each elastic cushion (unit: MPa)

The maximum stress of web plate and bottom plate of steel box girder mainly occurs at the intersection area. For type I rubber pad and type II rubber pad, the stress in the joint area between web, bottom plate, and U-shaped stiffener near the bottom plate is relatively high, as shown in Figure $\mathbf{4}$ and 5, the geometric shape of these areas changes suddenly and there is stress concentration phenomenon. With the increasing of the stiffness of elastic cushion (PTFE plate, steel plate), the vertical load is more distributed to the web, and the load proportion of the bottom plate decreases, as shown in Figure 6 and 7. At this time, the stress of the bottom plate is relieved, but the stress of the web is more unfavorable. 


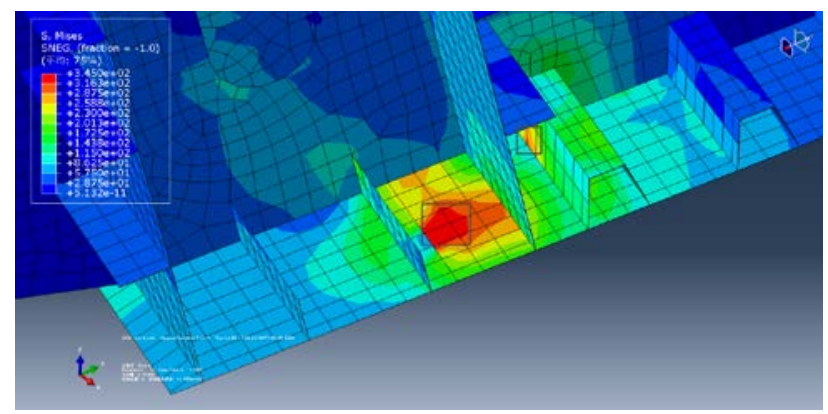

Figure 4. The most unfavorable area at bottom plate of steel box girder (type I rubber pad).

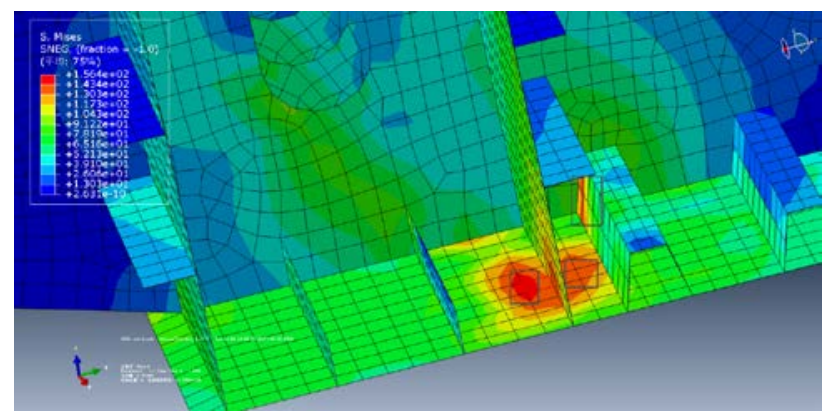

Figure 5. The most unfavorable area at bottom plate of steel box girder (type II rubber pad support).

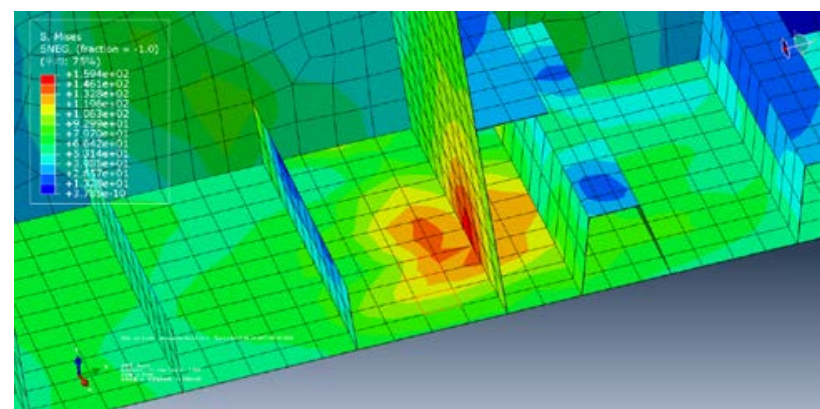

Figure 6. The most unfavorable area at bottom plate of steel box girder (PTEE plate).

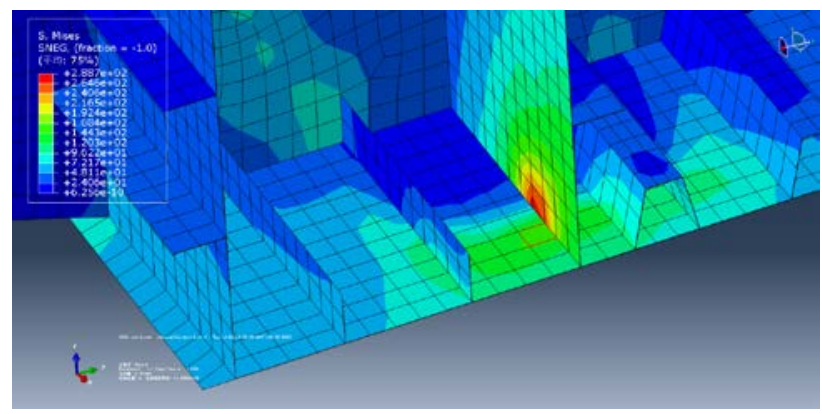

Figure 7. The most unfavorable area at bottom plate of steel box girder (steel plate support).

\subsection{Elastic cushion analysis}

The Mises stress of each elastic cushion of steel box girder during incremental launching is shown in Table 5.
From the table, the larger the stiffness of elastic cushion is, the more uneven the Mises stress distribution is, and the more unfavorable the stress of material is.

\begin{tabular}{ccc}
\hline \multirow{2}{*}{ Elastic cushion } & \multicolumn{2}{c}{ Mises stress } \\
\cline { 2 - 3 } & Maximum & Minimum \\
\hline Type I rubber pad & 1.46 & 0.13 \\
Type II rubber pad & 8.88 & 0.12 \\
PTEE plate & 15.58 & 0.25 \\
\hline
\end{tabular}




\begin{tabular}{ccc}
\hline \multirow{2}{*}{ Elastic cushion } & \multicolumn{2}{c}{ Mises stress } \\
\cline { 2 - 3 } & Maximum & Minimum \\
\hline Steel plate & 128.80 & 0.31 \\
\hline
\end{tabular}

Table 5. Mises stress range of elastic cushion

Compared with the supporting reaction of elastic cushion, the uneven phenomenon of supporting reaction is more and more obvious with the increasing of stiffness of elastic cushion; among them, the steel plate has the highest stiffness, and the supporting reaction force near the section of diaphragm and web is very high, and the supporting reaction force of other parts is small, which is not conducive to the stress of steel box girder. In addition, the stiffness of type I rubber cushion is too low and the jacking force required is large, which makes the force of temporary pier more unfavorable. Therefore, type II rubber pad and PTFE plate are more suitable as elastic cushion to support steel box girder.

\section{Conclusion}

In this paper, a large-span steel box girder cable-stayed bridge constructed by incremental launching construction is taken as the research object, and the overall and local mechanical behavior analysis is carried out. The following conclusions are drawn:

(1) Under all working conditions, the maximum positive stress appears at the lower edge of the steel box girder section on the temporary pier, that is, the safety state of the steel box girder is controlled by the negative bending moment at the top of the pier.

(2) With the increasing of the stiffness of the elastic cushion, the vertical load is more distributed to the web, and the load proportion of the bottom plate decreases. At this time, the stress of the bottom plate is relieved, but the stress of the web is more unfavorable.

(3) According to the analysis of supporting reaction force of elastic cushion, with the increase of stiffness of elastic cushion, the uneven phenomenon of supporting reaction force becomes more and more obvious; type II rubber cushion and PTEE plate are more suitable for supporting steel box girder with elastic cushion.

\section{References}

1. $\mathrm{Xu} \mathrm{T}$. Research on big-span steel box girder mechanical characteristics and construction monitoring (in Chinese). Changsha University of Science \& Technology; 2011.
2. Xie F. Influence analysis of the incremental launching of steel box girder and local stability control (in Chinese). International Conference on Civil, Architecture and Environmental Engineering; 2016.

3. Liu Y, Fan X. Dynamic reliability prediction for the steel box girder based on multivariate Bayesian dynamic Gaussian copula model and SHM extreme stress data (in Chinese). Structural Control \& Health Monitoring 2020; 27(6): 556-589.

4. Zhou L, Chen L,Xia Y, et al. Temperature-induced structural static responses of a long-span steel box girder suspension bridge. Journal of Zhejiang University - Science A 2020; 21(7): 580-592.

5. Benmohammed N, Ziane N, Meftah SA, et al. Distortional effect on global buckling and post -buckling behaviour of steel box beams. Steel and Composite Structures 2020; 35(6): 717-727.

6. Wang J, Xiang H. Geometric state transfer method for construction control of a large-segment steel box girder with hoisting installation (in Chinese). Journal of Zhejiang University - Science A 2020; 21(5): 382-391.

7. Wang H, Zhu Q. Temperature distribution analysis of steel box-girder based on long-term monitoring data (in Chinese). Smart Structures and Systems 2020; 25(5): 593-604.

8. Rosignoli M. Bridge launching. London: Thomas Telford Publishing; 2002.

9. Fontan AN, Diaz JM, Baldomir A, et al. Improved optimization formulations for launching nose of incrementally launched prestressed concrete bridges. Journal of Bridge Engineering 2011; 16(3): 461470.

10. Granata MF, Margiotta P, Arici M. A parametric study of curved incrementally launched bridges. Engineering Structures 2013; (49): 373-384.

11. Jung KH, Kim KS, Sim CW, et al. Verification of incremental launching construction safety for the Ilsun Bridge, the world's longest and widest prestressed concrete box girder with corrugated steel web section. Journal of Bridge Engineering 2011; 16(3): 453-460.

12. Wang J, Lin J, Xu R. Incremental launching construction control of long multispan composite bridges (in Chinese). Journal of Bridge Engineering 2015; 20(11): 165-178.

13. Ding S, Fang J, Zhang S, et al. A construction technique of incremental launching for a continuous steel truss girder bridge with suspension cable stiffening chords (in Chinese). Structural Engineering International 2020; (10): 1-6.

14. Schmidt H. Foundation and substructures of Hochmosel-Bridge - design and construction. Olaf Bautechnik 2019; 96: 21-30. 
15. Chai H, Song Y. Mechanical analysis for incremental launching construction of long-span continuous steel truss bridge. International Conference on Mechanics and Architectural Design (MAD); 2017.

16. Liang S, Lv G, Lin Y et al. Research on reasonable connections between webs and bottom plates in pre-pressed concrete composite box girder with corrugated steel webs. International Conference on Material Science and Civil Engineering (MSCE); 2017.

17. Zhang P. Force analysis and research of key problems in the incremental launching construction of bridge (in Chinese). Southwest Jiaotong University; 2014.

18. Li C, Wang J, Dong C, et al. Combining Ansys with
MATLAB to simulate and optimize the process of steel-box girder bridge by incremental launching method (in Chinese). Computer and Communications 2008; (6): 136-142.

19. Song Y. Study on structural performance of steel box girder bridge during the incremental launching construction stage (in Chinese). Beijing Jiaotong University; 2010.

20. Qu Y. Calculation and analysis on the steel box girder of span cable-stayed bridge incremental launching method (in Chinese). Southwest Jiaotong University; 2017.

21. GB 50017:2017 Standard for design of steel structures. 